\title{
A modernidade e o ocaso do social
}

\author{
Carlos A. Gadea*
}

TOURAINE, Alain. Un nuevo paradigma para comprender el mundo de hoy. Buenos Aires: Paidós, 2006.

A lguns anos atrás, Jean Baudrillard permitiu-me tomar contato, Ipela primeira vez, com um excitante diagnóstico acerca do suposto "ocaso do social". Em um trabalho intitulado Cultura y simulacro, Baudrillard perguntava-se, por exemplo, se as sociedades modernas respondiam a um progressivo processo de socialização ou dessocialização, admitindo que aquelas instituições que balizavam os "progressos do social" (urbanização, trabalho, produção, escolarização etc.) pareciam agora produzir e destruir o social de forma simultânea. A expansão dos meios de comunicação e a informação não teriam conseguido mais do que neutralizar as relações sociais, atomizando o social em sentido profundo.

Posteriormente, nas brilhantes reflexões de Zygmunt Bauman, foi possível encontrar os mesmos sintomas que definiriam nossa complexa contemporaneidade. Seu trabalho Modernidade líquida faz-nos deparar com uma modernidade em que as instituições e seus valores constitutivos parecem "derreter-se", perdendo sua rigidez e solidez características, para assumirem um inovador estado de fluidez e flexibilidade. A "modernidade líquida" de Bauman é aquela em que as lealdades a crenças e grupos de pertença esfumam-se no contexto das transformações socioculturais e dos novos dilemas da globalização.

Se alguém pretendesse achar possíveis semelhanças entre o pensamento de Baudrillard e as reflexões de Bauman acerca do destino do projeto histórico da modernidade, compreenderia que sua tarefa não é demasiadamente complicada. Mas, quais seriam os

Carlos A. Gadea é Doutor em Sociologia Política pela Universidade Federal de Santa Catarina (UFSC), Professor do Programa de Pós-Graduação em Ciências Sociais da Universidade do Vale do Rio dos Sinos (Unisinos) e Editor da Revista Ciências Sociais Unisinos. Endereço eletrônico: cgadea@unisinos.br. 
pontos comuns entre esses autores e as atuais e lúcidas reflexões do sociólogo francês Alain Touraine? À simples vista, pareceria que muito poucos. Lembremos que Touraine foi um dos principais introdutores da categoria "movimento social" na academia, gerando uma importante discussão em torno dos fenômenos sociais que tinham como eixo de análise a ação social e a emancipação política. Assim, Touraine (1965) foi reconhecido por sua definição de uma Sociologia cujo fundamento consistia em entender e explicar os movimentos sociais, com uma clara preocupação metodológica centrada nas categorias "modernidade", "democracia", "ação social" e "emancipação".

Não obstante, sua mais recente obra, Un nuevo paradigma para comprender el mundo de hoy, apresenta algumas surpresas, as quais poderíamos situar junto às reflexões de Baudrillard e Bauman. Sem dúvida, Touraine não pôde esconder sua posição intelectual como militante da "emancipação do sujeito", linha de pensamento e reflexão política que se achava sistematizada em uma obra anterior, intitulada ¿Podremos vivir juntos? Iguales y diferentes. Mas, a radicalidade de suas atuais análises transcende algum possível traço de ingenuidade interpretativa ou posse de correção política. O Touraine que estudava e teorizava sobre os movimentos sociais, o mundo do trabalho e os conflitos de classe foi cedendo o passo, com o tempo, a um intelectual cujo campo de análise estaria mais voltado para o "sujeito" da ação social.

Nesse sentido, considero que seu último livro é uma clara continuação de ¿Podremos vivir juntos? Iguales y diferentes. Nos dois casos, trata-se de brilhantes análises das mudanças sociais e culturais que as sociedades modernas experimentaram nas últimas três décadas. O que a última obra tem de diferente é uma evidente preocupação em incorporar nos diagnósticos uma postura metodológica que considera iniludível para a atualidade da Sociologia. De fato, ao afirmar que "ya no podemos, ya no debemos pensar socialmente los hechos sociales" (TOURAINE, 2006, p. 105), Touraine sugere que todo o corpo interpretativo em que a Ciência Social fundamentava sua organização e suas linhas de atuação já não é funcional para compreender o mundo de hoje. "Este paradigma que se debilita se ha construido sobre la idea de que la sociedad no tiene otro fundamento que lo social" (idem, p. 63), ou seja, um modelo que 
representa e organiza a existência em termos econômico-sociais, com base em categorias como classe, trabalho, produção, capital e mercado. Segundo Touraine, já não é possível explicar o mundo em que vivemos com base nessas categorias. $O$ processo de globalização, a carência de mecanismos institucionais de regulação social, o progressivo isolamento e a exclusão dos indivíduos são fatores que se apresentam como desencadeadores de uma maneira nova de pensar a realidade, conforme um paradigma de caráter cultural.

A "primeira modernidade", entretida nas vicissitudes da formação dos Estados modernos, os Estados nacionais e as revoluções políticas do século XIX, tinha substituído a ordem religiosa e sua explicação do mundo por uma ordem política e um novo paradigma explicativo da realidade. A "segunda modernidade", surgida com a industrialização, a urbanização e a escolarização, seria, então, a que conseguiria consolidar uma representação propriamente social da sociedade. Essa é uma representação que Touraine considera em crise, uma vez que, na atualidade, já não são mais os problemas e conflitos próprios dessa "segunda modernidade" que se apresentam com mais intensidade. Ao "ocaso do social", à dessocialização e à crise de todos os valores "sociais" deve acrescentar-se uma nova imagem: "El incremento de las reivindicaciones culturales, tanto bajo una forma neocomunitaria como de apelación a un sujeto personal y de reivindicación de derechos culturales. Hablábamos de 'actores sociales' y de movimientos sociales; en el mundo en que ya hemos entrado, tendremos que hablar con mayor frecuencia de sujetos personales y de "movimientos culturales"' (idem, p. 27).

Afirmar que vivenciamos a "destruição da sociedade" - ou seja, a destruição de uma visão social da vida social - representaria concordar com uma análise "não social" da realidade. Essa é a idéia central que Touraine aborda na primeira parte de seu livro, apresentando o conjunto de fenômenos sociais sintomáticos de desintegração e ruptura dos vínculos sociais. Na segunda parte, verifica-se um esforço por "construir la imagen de una sociedad que ha llegado a ser "no social', en la que las categorías culturales reemplazan a las categorías sociales, en la que las relaciones de cada cual consigo mismo son tan importantes como lo fuera antaño la conquista del mundo" (idem, p. 15). É nesse ponto que Touraine expõe as noções centrais do novo 
paradigma. Para aqueles que já tinham lido seu livro anterior, não será demasiadamente inovador. A descrição da "lógica instrumental" da modernidade não necessariamente sugeriria a desaparição dos atores sociais, que "están impacientes por afirmarse y lograr el reconocimiento de su libertad de sujetos" (idem, p. 307).

Recordando Foucault, podemos afirmar que a racionalização da sociedade conduz ao fortalecimento da lógica da integração social, do controle e, assim, à materialização de uma multiplicidade de mecanismos de poder asfixiantes para o indivíduo. Em um mundo em movimento, impossível de controlar, Touraine parece aderir a esses diagnósticos, assinalando que o único valor que se possui é um princípio de resistência e legitimidade do comportamento: a defesa do direito de existir como indivíduo e de não estar fora do mundo. Se esses direitos revestiam antes características políticas, portanto sociais, agora são eminentemente culturais, já que aludem a problemas relacionados à sexualidade, à religião e às diversas formas de vida. Invertendo a conhecida afirmação de Habermas acerca da "colonização do mundo da vida pelo sistema", Touraine pareceria sugerir que, na atualidade, o mundo privado invade o público e a cultura, a política.

O que Touraine manifesta com sua afirmação acerca do "ocaso do social" é parte de um amadurecimento intelectual que tem em sua matriz metodológica uma concepção ambígua da modernidade histórica: "La ruina de las sociedades tiene, sin duda, tantos aspectos negativos como positivos. La desocialización conduce a la destrucción de los lazos sociales, a la soledad, a la crisis de identidad, como he dicho, pero al mismo tiempo libera de pertenencias y reglas impuestas. Ahora bien, la modernidad no solamente no se encuentra debilitada por ello, sino que se convierte en la única forma de resistencia a todas las formas de violencia y a ella corresponde reconstruir instituciones que no estarán ya al servicio de la sociedad [...], sino al de la libertad creadora de cada individuo" (TOURAINE, 2006, p. 103-104). Segundo pode-se compreender, a modernidade é geradora de autênticas demandas de subjetivação, afirmação e reconhecimento de aspectos culturais e de identidade pessoal, processo de individualização que defende os direitos de cada um de controlar os juízos de valor sobre como se comportar perante os 
outros e consigo mesmo. Isso, sem dúvida, evidencia, para a Sociologia de Touraine, a grande característica da modernidade: a contínua tensão entre um universo instrumental (sob os contornos racionalizadores da sociedade) e um universo simbólico (caracterizado pelas experiências de produção e afirmação dos sujeitos sociais).

Touraine propõe, uma vez mais, uma observação de nossa contemporaneidade que não oferece uma única imagem, mas, sim, duas: a racionalização e a subjetivação, o universo instrumental e o universo simbólico, a socialização e a dessocialização, a subjugação dos indivíduos e a liberdade dos sujeitos. Na base de suas análises, encontra-se, novamente, a idéia de que, na atualidade, "existen, por una parte, fuerzas de destrucción de los actores sociales que actúan invocando la necesidad natural y, frente a ellas, figuras del sujeto (religiosas, políticas, sociales o morales) que resisten a lo que amenaza a la libertad. Entre las dos se mantienen (o incluso se refuerzan) instituciones que se esfuerzan por dar forma a la autonomía de lo social" (idem, p. 31).

Para Touraine, é na análise dessas tensões que deve situarse uma Sociologia que defenda o campo de sua atuação. Embora a modernidade tenha sido sempre impulsionada pela idéia de sociedade, "hoy sólo puede desarrollarse desembarazándose de ella, combatiéndola incluso, y apoderándose del sujeto, que es cada vez más directamente opuesto a la idea de sociedad" (idem, p. 103). Assistimos, então, a uma Sociologia sem sociedade? Talvez, considerando-se que não é possível, na atualidade, uma Sociologia que não reconheça a noção de sujeito nem os aspectos culturais como de inevitável centralidade analítica. Touraine tem transitado de uma Sociologia dos movimentos sociais para uma Sociologia do "sujeito" da ação social. Em seu último livro, é notório seu interesse por analisar a potencialidade expressiva que subjaz à idéia de sujeito e ator social. É que, para Touraine, cada vez que houve algum tipo de retrocesso, reforçamo-nos - na condição de atores sociais - como sujeitos pessoais, uma virada empírica que sugeriria uma consequiente virada teórica e analítica. 


\section{Referências bibliográficas}

BAUDRILLARD, J. Cultura y simulacro. Barcelona: Kairós, 1978.

BAUMAN, Z. Modernidade líquida. Rio de Janeiro: J. Zahar, 2001. TOURAINE, A. Sociologie de l'action. Paris: Seuil, 1965.

. ¿Podremos vivir juntos? Iguales y diferentes. Buenos

Aires: Fondo de Cultura Económica, 1997. . Un nuevo paradigma para comprender el mundo de

hoy. Buenos Aires: Paidós, 2006. 